\title{
THE COST OF THE CITY WORKER'S FAMILY BUDGET: COMMENT
}

Richard A. Engels

From my perspective in an economic research and information center, I must lend all possible encouragement to Richard Hurd in developing an estimating technique for the City Worker's Family Budget (CWFB). The interest expressed in this type of measure from those involved in local and regional planning, marketing, the state legislature, the general public, and from other researchers in Tennessee and othe $r$ areas of the Nation is difficult to overstate. On the average, our Center receives one call every other week requesting comparative cost of living data. And from all indications, this is representative of Centers of its type around Nation.

At present there is insufficient areal coverage from the Bureau of Labor Statistics CWFB, and the Current Price Indexis designed as a limited measure of inflation rather than as a "cost of living index." The demand for independent research in this area should be expected to increase as fiscal management and planned economic controls becomes more a part of everyday life.

In an effort to support work of this sort let me make several comments regarding the paper. First, from a very pragmatic standpoint, the equation developed in the paper would be far more useful if it were to rely on other than decennial Census of Population and housing data. Even if we were to grant for the moment that the 1959 equation may be applied to subsequent years, there are no data to plug into the formula. Recall that the variables include housing cost, housing quality, a wage index, and the percent of the population that is nonwhite. Since these are already being used in place of the full CWFB, what is being suggested is proxy variables for the proxy variables. It is doubtful that this would demage the quality of the equation substantially but would broaden its application significantly.

We might extend this even further to suggest that a truly abridged $\mathrm{CWFB}$ methodology be attempted rather than to continue within the regression framework. The CWFB data requirements are in sixmajor categories: food, shelter, transportation, medical care, other goods and services, and other costs. ${ }^{1}$ The food segment contains four primary data sources and presents the most difficulties in constructing an abbreviated alternate schedule of costs. The 1965 USDA Household Food Consumption Study forms the basis from which the BLS list and quantities of food items are compiled. Both the USDA study and the BLS list are readily accessible to the researcher. Equally as accessible are local public school lunch costs. Somewhat more problematic are the ratios of city to regional prices constructedinternally at BLS. Perhaps the personal income estimates developed by the Bureau of Economic Analysis for local areas or some related series might substitute here. Even more troublesome are the price estimates deriving from the Current Price Index. Indentifying substitute sources for data similar to the CPI no doubt would provide some frustrations but hopefully would not be insurmountable.

Two additional concerns relate particularly to the statistical tests and evaluations of estimationaccuracy. First, one focus of the research reported in the paper is to develop a procedure for estimating the $1959 \mathrm{CWFB}$ for areas not covered in the standard BLS program. Even more compelling is the potential for estimating the CWFB for other years. Use of the three Spearman rank correlations permits limited validation of the 1959 rankings 
only. We have anindication that the 1959 estimated rankings correlate about as well with the 1966 CWFB rankings as the actual 1959 CWFB figures do. However, the potential user would take a great deal of comfort from knowing what type of error he should expect in using the 1959 equation for subsequent years. It is not just a question of anticipating a serious error one percent or five percent of the time, depending uponconfidence limits, but rather "will I average 5 percent or 15 percent errorif I accept and use the formua?" It would also be helpful to have an indicationas to algebraic direction of bias, if any, as well as absolute error.

The second concern is more accurately a curiosity as to the make-up of the simple correlation matrix. It must be granted that the variables have been selected on the basis of their "fit" in the solution as it has been conceived. The rationale "hangs together"logically. It is likely, however, that (1) there is substantial intercorrelation among the independent variables and (2) that most of the variance in the dependent variables is likely to have been explained by the housing cost and wage variables. BLS has indicated that approximately 50 percent of the CWFB is accounted for by the housing cost and food entries along. 2 It would be advisable for a user of the equation to be aware of the sensitivity of these two data items as he gathers and checks the basic data, prepares the estimates, and attempts to interpret the results.

Finally, a note on comparability. The 1959 and 1966 CWFB a re not the same measure. As BLS indicates, "... it (the 1959 CWFB) was considered 'interim, ' pending a more complete review of the procedures and the availability of data from the Bureau's Survey of Consumer Expenditures in 196061. The interim budget was priced only once, in autumn 1959, in 20 large cities." And "The present study (1966) differs from the earlier budgets in two major respects. These differences have affected the level of the 1966 costs and comparative living cost indexes, particularly in relation to the costs and indexes of the 1959 interim budget. "3 The most striking alteration was in the standard list of items comprising the "modest but adequate" budget.

Moreover, we should not expect a high correlation coefficient or coefficient of determination among 1959 and 1966 CWFB results, even with a rank correlation measure. With a consistent operational definition of budget, the correlation measures may increase noticeably. 


\section{REFERENCES}

1. U.S. Department of Labor, Bureau of Labor Statistics, " 3 Standards of Living for an Urban Family of Four Persons," Bulletin No. 1570-5 (Spring 1967), pp. 41-48.

2. U.S. Department of Labor, Bureau of Labor Statistics, "City Worker's Family Budget for a Moderate Living Standard," Bulletin No. 1570-1 (Autumn, 1966), p. 16. In 1967 the percentage attributable to food and shelter had increased to 60 percent; U.S. Department of Labor, op. cit., p. 8.

3. Ibid., p. vi. 